\title{
Role of lumbar disc degeneration and genetic variation in chronic low back pain
}

\author{
Romain S Perera \\ Department of Allied Health Sciences, Faculty of Medicine, University of Colombo, Sri Lanka
}

\section{Article information}

Total number of

Words 3161

Author has no conflicts of interest to declare

Keywords: Low back pain, Lumbar disc degeneration, Genetic variations, Lumbar spine, Disc herniation, Modic changes

Date of submission: 12.05 .2018

Date of acceptance: 10.06 .2018

Author responsible for correspondence:

Dr Romain Shanil Perera

Department of Allied Health Sciences

Faculty of Medicine, University of Colombo

0773412975 Email:romainsperera@gmail.com

http://orcid.org/0000-0002-9682-5642

DOI: http://doi.org/10.4038/cjms.v55i1.4931

\begin{abstract}
Low back pain (LBP) is a common symptom and leading cause of disability worldwide. The majority of LBP is due to mechanical causes. However, it is challenging to accurately identify a causative factor for chronic LBP and it is considered a multifactorial condition. Lumbar disc degeneration (LDD) is frequently seen in patients with chronic LBP, but radiological features of disc degeneration is poorly correlated with the symptoms of LBP. The role of radiological investigations in chronic LBP is controversial, but it is frequently used in primary care despite the recommendation to use it only on selected patients with serious underlying pathology or progressive neurological symptoms. Pathophysiology of LDD is complex and is mainly genetically determined. Genetic variation may help in classifying varying degrees of LBP in patients with LDD. Improved understanding of the role of radiological features in LDD and genetic investigations help in advancing personalized care and implementing innovative strategies in the management of chronic LBP.
\end{abstract}

\section{Introduction}

Low back pain (LBP) is an extremely common health issue which affects individuals in all age groups. Most LBP is self-limiting and resolves in less than three months. It is estimated that in about $23 \%$ of those who experience LBP, symptoms persist for more than 3 months [1]. Recurrences are common among this group, with up to $85 \%$ experiencing recurrences throughout their lifetime [2]. Although the global prevalence of LBP was $9.17 \%$ in 2012, Global Burden of Disease Study highlighted that the LBP is the number one cause for years lived with disability in many regions of the world [3]. It also reported that LBP and neck pain has been the number one cause for years lived with disability in Sri Lanka since 2005. More importantly, there has been an almost $20 \%$ increase in disease burden from 2005 to 2016 in Sri Lanka [3].

LBP affects all aspects of life including physical, mental, and social well-being. It influences the essential daily activities of personal life and their roles in the family, workplace and in the community [4].
LBP is the commonest cause of musculoskeletal health issues and disability in several occupational groups of Sri Lanka [5-8].

Disability related to LBP has become a major issue in work places of low and middle income countries due to several reasons. Most of the employees are working in informal and daily paid employments. Occupational musculoskeletal health policies are poorly monitored in these countries. In addition, there are less opportunities to modify the job environment according to the requirements of the employee suffering from the disability due to LBP. Costs related to LBP are directly due to medical bills and non-medical costs (transportation for appointment and informal help etc.) and indirectly due to the loss of work and productivity [9]. Over the years, the burden of the LBP has increased, and today more than 100 billion dollars is spent annually around the world for the management of LBP [10].

There are two main types of LBP: mechanical and non-mechanical [11]. Majority of LBP is due to mechanical causes [12].

This is an open-access article distributed under the terms of the Creative Commons Attribution 4.0 International License, which permits unrestricted use, distribution and reproduction in any medium provided the original author and source are credited. 
Most cross sectional and cohort studies have identified the presence of some degree of Lumbar Disc Degeneration (LDD) in patients with chronic LBP [13]. LDD is a common finding in aging spine and symptoms of chronic LBP are not always correlated with the radiological features of LDD [14]. However, routine radiological investigations (X-ray and MRI scan of lumbar spine) are carried out in patients with LBP despite the recommendation to limit these investigations to patients who do not respond to treatment, or who have signs of neurological involvement or serious underlying pathology [15].

Environmental and psychological factors play a role in modifying the development of LBP [16]. Recent research in LBP highlight that the role of genetic factors in LDD and LBP could be as high as 30 to $46 \%$ [17]. Each patient has unique genetic profile and genetic testing would provide better understanding of the pathophysiology of LDD and pain modulation, allowing development of innovative new therapeutic techniques in the management of LBP. This review gives an overview of the clinical features and causes of LBP, the pathophysiology of LDD and its role in chronic LBP and the role of genetic variation as a modifying factor in LDD and LBP.

\section{Clinical features and causes of low back pain}

LBP is a symptom, not a disease. It is defined as pain, muscle tension, or stiffness localized below the costal margin and above the inferior gluteal folds, with or without leg pain [18]. Some patients may have neurological symptoms associated with LBP such as radicular pain or radiculopathy which is a result of a nerve root involvement [9]. Identifying a definite cause for LBP is challenging in most cases [19] and such pain is defined as nonspecific LBP [20]. Majority of non-specific LBP is mechanical in nature where the main feature is pain which starts during day time and gets worse towards evening. Mechanical LBP is associated with daily activities, particularly repeated bending, lifting, prolonged standing, sitting and walking [12]. Non-specific LBP may relate to the mechanical injuries of spinal structures and surrounding soft tissues such as sprains, strains and complications of LDD. However, there are few (approximately 3\%) serious causes of chronic LBP such as malignancy (primary or secondary), infection, vertebral fracture and ankylosing spondyloarthritis [21] which need urgent identification and specific management of the cause [9].

\section{Anatomy of the lumbar disc}

Lumbar discs are fibrocartilage pads between adjacent lumbar vertebral bodies which distribute compressive loading evenly on to the vertebral bodies. Lumbar disc consists of a central nucleus pulposus, surrounding annulus fibrosus and cartilage end plates [22]. Extracellular matrix of the nucleus pulposus is made up of hydrated proteoglycan gel and is held together by a loose network of collagen and elastin fibres. Annulus fibrosus is formed by $15-$ 25 concentric lamellae made up of parallel arrays of collagen fibres within a thin proteoglycan gel. End plate separates the nucleus pulposus and annulus fibrosus from the vertebral bodies above and below [23,24].

The three-joint segment formed by the intervertebral disc and the two facet joints at the same level is called the motion segment of the spine. This is a very important joint complex when it comes to movement, flexibility and stability of the spine, and the lumbar disc is a key component of this motion segment. The lumbar disc acts as a shock absorber, absorbing some of the compressive loads and transmitting the rest along the spine [9]. As the loading pressure increases, lower levels of the spine, specifically the lumbar spine becomes more vulnerable to injuries [25].

\section{Lumbar disc degeneration and complications}

The pathophysiology of LDD is complex. Disc degeneration starts in early teenage years. Recent studies have argued that age related changes of the disc and LDD are two different processes. With aging, there is a reduction of proteoglycans leading to loss of hydration of the disc. There is increased cross linking of collagen fibres turning the disc into a stiffer and fibrous structure. In contrast, in LDD, the age related biochemical and functional changes are exaggerated. Disc degeneration is characterised by structural damage to the disc matrix and imbalance between the matrix synthesis and catabolism leading to loss of extracellular matrix [26]. Catabolic pathways become more prominent with aging and degeneration. This process is further accelerated by increased release of inflammatory cytokines. The imbalance between the degradation and inhibitory pathways is also increased with disc degeneration $[27,28]$. Our 
recent cross sectional study done in Sri Lanka reported that advanced degenerative features of the spine were present in younger patients (2029 years) with chronic LBP raising the question that LDD may not be entirely age related [29].

Further, decompression in nucleus pulposus and high compressive stress in the annulus fibrosus cause the annulus to bulge radially outwards or to collapse inward resulting in disc height loss/disc space narrowing. Annular fissures/tears appear in the disc with degeneration due to the separations between annular fibres or breaks through fibres that extend radially, transversely, or concentrically involving one or several layers of annular lamellae. Part of the nucleus pulposus, cartilage or fragmented annular tissue can be displaced beyond the intervertebral disc space through the annular fissure resulting disc herniation [13]. In addition, end plate and adjacent vertebral bone marrow show degenerative changes which are called Modic changes in parallel to the nuclear and annular degeneration of the disc [30].

\section{Pathophysiology of discogenic pain}

The exact pathology behind the relationship between LDD and chronic LBP is still unknown and several possible explanations have been described. There are less nerve fibres in the inner parts of the lumbar disc. Therefore, it is insensitive to painful stimuli under normal conditions. However annular tears and end plate ruptures, promote nerve in growths to the inner part of the lumbar disc. Pain receptors are stimulated when they come into contact with the leaked nuclear material from the disc [31]. Nerve entrapment by the herniated discs cause radicular pain and radiculopathy. Increased release of inflammatory cytokines stimulate nearby nerve roots and trigger pain [32]. With the loss of proteoglycans, the disc's hydrostatic pressure falls and the load bearing function of the disc is disrupted. Abnormal load distribution on adjacent apophyseal joints promotes osteoarthritis and pain [33].

\section{Role of radiological features of lumbar disc degeneration in chronic low back pain}

Radiological investigations are routinely used in the management of LBP in primary care. However, its role in LBP is controversial. The main purpose of radiological investigations in LBP is related to assisting the diagnosis, guiding treatment and informing the patient about prognosis [34].
$\mathrm{X}$-ray lumbar spine is a common diagnostic investigation in low and middle income countries, but what is seen is limited to bony changes related to disc degeneration. X-ray is cost effective, but exposure to high radiation is a disadvantage. Disc space narrowing and anterior osteophytes are the main x-ray features of LDD and they are highly correlated with the morphological stages of LDD [35]. Several studies have shown that disc space narrowing increases the likelihood of LBP [36-39]. The association of anterior osteophytes with chronic LBP is considered as non-significant unless there are large anterior osteophytes [40]. Most of these studies are done as population based studies and restricted to middle aged/elderly individuals or one gender. In contrast, clinic based studies have failed to identify a significant association between the X-ray features of LDD and intensity of LBP or disability $[29,41,42]$.

Magnetic Resonance Imaging (MRI) generates a more detailed image of the disc and complications related to LDD [13]. However, its diagnostic value in chronic LBP is debatable as MRI features of disc degeneration, annular tears and disc herniation can be seen even in asymptomatic individuals [43]. Nevertheless, a recent systematic review and meta-analysis reported that several MRI findings (Modic type I, disc extrusion and spondylolysis) are common in patients with low back pain less than 50 years compared to the asymptomatic individuals $[9,44]$. Among the patients with LBP, only the Modic changes have a reasonable predicting value of the intensity of pain and outcome of the treatment in chronic LBP, especially in young patients [45-47].

Frequently, there are multiple degenerative radiological findings in multiple levels of the spine in patients with chronic LBP. However, it is difficult to identify which pathology leading to the radiological changes, contributes most to the patients' symptoms. Therefore, in such situations, utilization of MRI findings as a guide to target treatment is limited [48]. Most studies have assessed the association of a single radiological finding of disc pathology with LBP and/or treatment outcome, rather than assessing effect of a combination of radiological findings (aggregate score) at multiple levels of lumbar spine [49]. A few population based studies have reported that presence of a combination of radiological features is strongly associated with both the presence of LBP and recurrence of LBP $[48,50]$. However, there is a lack of studies 
exploring the association between combination of radiological features with intensity of pain and treatment outcomes among patients with LBP in primary care [47].

In Sri Lanka, clinicians regularly use x-ray lumbar spine to diagnose LDD and guide the treatment. Our recent cross sectional study in patients with chronic mechanical LBP, revealed that x-ray features, specially disc space narrowing and anterior osteophytes were not associated with intensity of pain or severity of disability. Lumbar spondylolisthesis was the only x-ray feature which predicted increased severity of disability [29]. Lumbar spondylolisthesis is an advanced degenerative feature and it leads to alignment instability in the spine [13]. Similarly, MRI features of LDD could not explain the intensity of pain and severity of disability. In the follow up cohort, presence of disc herniation was associated with poor improvement of intensity of pain after three months. Furthermore, aggregate MRI findings predicted poor treatment outcome where the patients with 3-4 MRI findings had increased likelihood of poor improvement in pain intensity [unpublished data].

\section{Other risk factors of chronic low back pain}

Age, gender, and body mass index (BMI) are associated with chronic LBP [9]. According to our study findings, proportions of patients with chronic LBP increased with aging, up to the age of 60 years with intensity of pain and severity of disability being significantly high in female patients [29]. In addition, we found that patients with chronic LBP have higher BMI (29) compared to the general population of Sri Lanka (BMI values were taken from the Sri Lanka Diabetes, Cardiovascular Study) [51]. Several systematic reviews have reported that lifestyle factors such as smoking, posture and level of physical activities are also associated with an increased incidence of LBP and development of persistent pain in addition to the age, gender and BMI [9]. Furthermore, the presence of a previous episode of LBP [52] and psychological factors such as depression and distress [53] have increased risk for recurrence of LBP. There is a growing body of evidence that genetic variation is associated with degenerative features of the spine and symptoms of LBP [20].

\section{Genetic variations and chronic low back pain}

The associations of genetic variations with radiological features and back pain is complex. Candidate gene approach is the common approach for genetic testing and genes are selected based on the prior knowledge about the gene function and its relevance to the mechanism of the disease/phenotype being studied. Single nucleotide variation (SNV) is the commonest type of genetic variation. SNVs result in substitution of a single nucleotide at a specific position in the genome. SNVs are responsible for the observable characteristics of a person or physical phenotypes as well as clinical phenotypes [54].

\section{Role of genetic variations in lumbar disc degeneration}

Disc degeneration is genetically determined and is modified to some degree by behavioural and environmental factors [55]. Genetic variations can explain why some individuals develop early and severe LDD compared to others in the same age group. Heredity can determine the size, shape and mechanical and functional properties of the spinal structures. As a result, certain discs are weakened and matrix can be physically disrupted even due to activities of normal daily living [56,57]. There are four types of genes associated with different phenotypes related disc degeneration. They include genes which code for structural components of the lumbar disc (collagen, aggrecan, elastin etc..), genes coding catabolic enzymes (e.g. matrix metalloproteinases and a disintegrin and metalloproteinase with thrombospondin motifs) and regulatory enzymes (eg. tissue inhibitors of metalloproteinases), genes affecting regulation of the inflammation (interleukins), and genes encoding molecules such as vitamin D which are essential components of normal bone and calcium homeostasis. SNVs of the genes encoding structural proteins such as COLlAl, COL9A2, COL9A3, COLIIAI and ACAN primarily increase the risk of disc herniation [5860]. In contrast, SNVs of the inflammatory genes including ILIA, ILIB and IL6 and catabolic genes such as MMP3, ADAMTS4 and ADAMTS5 primarily increase the risk of LDD and Modic changes [61-66]. Certain genetic variations have interethnic variation where some SNVs have stronger or no effect on LDD depending on the type of ethnicity (eg. FokI SNV of VDR Hispanics have higher risk for disc 
degeneration where the individuals of Caucasian decent have no effect) [67].

\section{Role of genetic variations in intensity of low back pain}

Similarly, genetic variations can affect the candidate genes in pain modulation, transduction, transmission, and conduction pathways. There is evidence that SNVs of the genes coding for catechol-O-methyltransferase (COMT), opioid receptors (OPRM1, OPRD1), transient receptor potential (TRPVI, TRPAI), fatty acid amide hydrolase $(F A A H)$ and $\alpha$ subunit of voltage gated sodium channel (SCN9A) are associated with the intensity of pain (68). In addition, the genes associated with the different phenotypes of LDD are also associated with the peripheral modulation of pain $[68,69]$.Therefore genetic variation may help in classifying varying degrees of LBP in patients with LDD.

Sri Lankan population has a unique genetic profile [70]. We have reported that radiological features of LDD is not entirely age related based on the results of the genetic association study done in Sri Lankan patients with chronic LBP [60]. We found that SNVs of the candidate gene of aggrecan metabolic pathway were associated with severity of LDD, Modic changes and disc herniation. Further, several SNVs associated with the degenerative changes were associated with higher intensity of pain, severe disability and poor treatment outcome. Most of these associations between the respective SNVs and radiological/clinical phenotypes are described for the first time in the literature and it further strengthens the fact that Sri Lankans have an unique genetic profile. In addition in-silico functional analysis identified several functionally important SNVs $[60,66]$. These need to be confirmed with functional genetic studies to recognise the genetic expression and its function at molecular level.

Although there are several gene loci which are associated with LDD and pain, it is difficult to decide whether the association is due to either a single gene variant with an effect of higher magnitude or multiple loci with small effects [71]. Most of the identified SNVs associated with LDD/ pain are located in intronic regions of the DNA sequence. The exact roles of most of the identified genetic variations are still under investigation. Most of these SNVs are acting as markers for functional variations elsewhere in the same or nearby genes. However, identification of associated genetic variants with LDD would provide insight into the process of degeneration, and will help to recognize individuals who are at risk of early and severe LDD [72].

\section{Key-points and future directions}

Chronic mechanical LBP is a disabling symptom which affect individuals of all age groups. Most patients with chronic LBP have disc related degenerative features. Current evidence is insufficient to decide the role of radiological findings of LDD and its complications on predicting the onset, course and recurrence of LBP. X-ray of lumbar spine is mainly indicated if there is a suspicion of a vertebral fracture in high risk patients with osteoporosis or long term steroid use [73]. MRI scan of lumbar spine should be considered in those with chronic nonspecific LBP, with persisting symptoms and progressive neurological symptoms or signs [74]. Consideration of other risk factors such as environmental, psychological and occupational are important in decision making during management. Genetic profiling can be used to predict the severity of disc related degenerative features, symptoms and treatment outcome of the LBP. The cost of genetic testing comes down day by day. However, more research is needed to confirm the results of previous studies using larger sample numbers in multiple ethnicities. In addition, functional genetic studies are required to confirm the genetic expression and its function in molecular level. These measures will optimise the management of chronic LBP saving billions of money and reducing the disease burden.

\section{Acknowledgments}

The work mentioned in this article was funded by the University Grants Commission, Sri Lanka (UGC/ ICD/2/RG2011/02/08) and the University of Colombo, Sri Lanka (AP/3/2012/ PG/03). The author acknowledges Prof. Vajira HW Dissanayake, Prof. Aranjan L Karunanayake, Dr. Lalith S. Wijayaratne, Prof. Upul Senarath and Dr. Harsha Disanayake for their expert opinion. A special thanks to Dr. Dinesha Jayasinghe for language editing.

\section{Competing Interests}

Author has no conflicts of interest to declare. 


\section{References}

1. Vos T, Flaxman AD, Naghavi M, et al. Years lived with disability for 1160 sequelae of 289 diseases and injuries 19902010: a systematic analysis for the Global Burden of Disease Study 2010. Lancet 2012;380(9859):2163-96. doi: 10.1016/S0140-6736(12)61729-2

2. Hoy D, Brooks P, Blyth F, et al. The epidemiology of low back pain. Vol. 24, Best Pract Res Clin Rheumatol 2010. p. 769-81. doi: 10.1016/j.berh.2010.10.002.

3. Vos T, Abajobir AA, Abbafati C, et al. Global, regional, and national incidence, prevalence, and years lived with disability for 328 diseases and injuries for 195 countries, 1990-2016: A systematic analysis for the Global Burden of Disease Study 2016. Lancet 2017;390(10100):1211-59. doi: 10.1016/S0140-6736(17)32154-2.

4. MacNeela P, Doyle C, O'Gorman D, et al. McGuire BE. Experiences of chronic low back pain: a meta-ethnography of qualitative research. Health Psychol Rev 2015;9(1):63-82. doi: 10.1080/17437199.2013.840951.

5. Karunanayake AL, Pathmeswaran A, Kasturiratne A, et al. Risk factors for chronic low back pain in a sample of suburban Sri Lankan adult males. Int J Rheum Dis 2013;16(2):203-10. doi: 10.1111/1756-185X.12060.

6. Noda M, Malhotra R, DeSilva V, et al. Occupational risk factors for low back pain among drivers of three-wheelers in Sri Lanka. Int J Occup Environ Health 2015;21(3):216-24. doi: 10.1179/2049396714Y.0000000071.

7. Harshani SR, Abeysena C. Musculoskeletal symptoms, skin disorders and visual impairment among fishermen in the divisional secretariat division of Kalpitiya. Ceylon Med J 2015;60(3):90-4.

8. Warnakulasuriya SSP, Peiris-John RJ, Coggon D, et al. Musculoskeletal pain in four occupational populations in Sri Lanka. Occup Med (Lond). 2012;62(4):269-72. doi: $10.1093 /$ occmed/kqs057.

9. Hartvigsen J, Hancock MJ, Kongsted A, et al. Low back pain 1: what low back pain is and why we need to pay attention. Lancet 2018. doi: 10.1016/S0140-6736(18)30480-X.

10. Buchbinder R, Blyth FM, March LM, et al. Placing the global burden of low back pain in context. Best Pract Res Clin Rheumatol 2013;27(5):575-89. doi: 10.1016/j.berh.2013.10.007.
11. Deyo RA, Weinstein JN. Low back pain. N Engl J Med 2001;344(5):363-70.

12. Walker BF, Williamson OD. Mechanical or inflammatory low back pain. What are the potential signs and symptoms? Man Ther 2009; 14(3):314-20.

doi: 10.1016/j.math.2008.04.003.

13. Modic MT, Ross JS. Lumbar degenerative disk disease.

Radiology 2007;245(1):43-61.

14. Videman T, Battié MC, Gibbons LE, et al. Associations between back pain history and lumbar MRI findings.

Spine 2003;28(6):582-8.

15. Chou R, Qaseem A, Owens DK, et al. Diagnostic imaging for low back pain: advice for high-value health care from the American college of physicians. Ann Intern Med 2011;154(3):181-9. doi: 10.7326/0003-4819-154-3-20110201000008 .

16. Jonsdottir J, Rainero G, Racca V, et al. Functioning and disability in persons with low back pain. Disabil Rehabil 2010;32 Suppl 1:S78-84. doi: $10.3109 / 09638288.2010 .514970$.

17. Battié MC, Videman T, Levalahti E, et al. Heritability of low back pain and the role of disc degeneration. Pain 2007;131(3):272-80.

18. Airaksinen O, Brox JI, Cedraschi C, et al. Chapter 4 European guidelines for the management of chronic nonspecific low back pain.

Eur Spine J 2006;15:s192-300.

19. Patrick N, Emanski E, Knaub MA. Acute and chronic low back pain. Med Clin North Am 2014;98(4):777-89. doi: 10.1016/j.mcna.2014.03.005

20. Manek NJ, MacGregor AJ. Epidemiology of back disorders: prevalence, risk factors, and prognosis. Curr Opin Rheumatol 2005;17(2):134-40

21. Deyo RA, Weinstein JN. Low back pain. N Engl J Med 2001;344(5):363-70.

22. Boos N, Weissbach S, Rohrbach H, et al. Classification of age-related changes in lumbar intervertebral discs: 2002 Volvo Award in basic science. Spine 2002;27(23):2631-44.

23. Roughley PJ. Biology of intervertebral disc aging and degeneration: involvement of the extracellular matrix. Spine 2004;29(23):2691-9.

24. Sivan SS, Wachtel E, Roughley P. Structure, function, aging and turnover of aggrecan in the intervertebral disc. Biochim Biophys Acta 2014;1840(10):3181-9. doi: 10.1016/j.bbagen.2014.07.013. 
25. Raj PP. Intervertebral disc: anatomyphysiology-pathophysiology-treatment. Pain Practice 2008;8(1):18-44.

26. Adams MA, Dolan P. Intervertebral disc degeneration: evidence for two distinct phenotypes. J Anat 2012;221(6):497-506. doi: 10.1111/j.1469-7580.2012.01551.x.

27. Wuertz K, Vo N, Kletsas D, Boos N. Inflammatory and catabolic signalling in intervertebral discs: the roles of NF-KB and MAP kinases.

Eur Cell Mater 2012;23:103-9.

28. Wang J, Markova D, Anderson DG, et al. TNF- $\alpha$ and IL- $1 \beta$ promote a disintegrinlike and metalloprotease with thrombospondin type I motif-5-mediated aggrecan degradation through syndecan-4 in intervertebral disc. J Biol Chem 2011;286(46):39738-49. doi: 10.1074/jbc.M111.264549.

29. Perera RS, Dissanayake PH, Senarath U, et al. Associations between disc space narrowing, anterior osteophytes and disability in chronic mechanical low back pain: a cross sectional study. $B M C$ Musculoskelet Disord 2017;18(1):193. doi: 10.1186/s12891-017-1562-9.

30. Lotz JC, Fields AJ, Liebenberg EC. The role of the vertebral end plate in low back pain. Global Spine J 2013;3(3):153-63. doi: 10.1055/s-0033-1347298.

31. Fagan A, Moore R, Roberts BV, et al. ISSLS prize winner: the innervation of the intervertebral disc: a quantitative analysis. Spine 2003;28(23):2570-6.

32. Aoki Y, Nakajima A, Ohtori S, et al. Increase of nerve growth factor levels in the human herniated intervertebral disc: can annular rupture trigger discogenic back pain? Arthritis Res Ther 2014;16(4). doi: 10.1186/ar4674.

33. Videman T, Nurminen M. The occurrence of anular tears and their relation to lifetime back pain history: a cadaveric study using barium sulfate discography. Spine 2004;29(23):2668-76.

34. Jensen TS. What is the role of imaging in low back pain patients in primary care? In: $9^{\text {th }}$ interdisciplinary world congress on low back and pelvic girdle pain 2016. p. 274-8.

35. Benneker LM, Heini PF, Anderson SE et al. Correlation of radiographic and MRI parameters to morphological and biochemical assessment of intervertebral disc degeneration.

Eur Spine J 2005;14(1):27-35.

36. Pye SR, Reid DM, Smith R, et al. Radiographic features of lumbar disc degeneration and self-reported back pain. J Rheumatol 2004;31:753-8.
37. de Schepper EI, Damen J, van Meurs JB, et al. The association between lumbar disc degeneration and low back pain: the influence of age, gender, and individual radiographic features Spine.

2010;35(5):531-6.

doi: 10.1097/BRS.0b013e3181aa5b33.

38. Wang YX, Griffith JF, Zeng XJ, et al.

Prevalence and sex difference of lumbar disc space narrowing in elderly chinese men and women: osteoporotic fractures in men (Hong Kong) and osteoporotic fractures in women (Hong Kong) studies. Arthritis Rheum 2013;65(4):1004-10. doi: 10.1002/art.37857.

39. Cho NH, Jung YO, Lim SH, et al. The prevalence and risk factors of low back pain in rural community residents of Korea. Spine 2012;37(24):2001-10.

doi: 10.1097/BRS.0b013e31825d1fa8.

40. Goode AP, Marshall SW, Renner JB, et al. Lumbar spine radiographic features and demographic, clinical, and radiographic knee, hip, and hand osteoarthritis. Arthritis Care Res 2012;64(10):1536-44. doi: 10.1002/acr.21720.

41. Kerry S, Hilton S, Dundas D, et al. Radiography for low back pain: a randomised controlled trial and observational study in primary care. Br J Gen Pract 2002;52(479):469-74.

42. Hicks GE, Morone N, Weiner DK. Degenerative lumbar disc and facet disease in older adults: prevalence and clinical correlates. Spine 2009;34(12):1301. doi: 10.1097/BRS.0b013e3181a18263.

43. Brinjikji W, Luetmer PH, Comstock B, et al. Systematic literature review of imaging features of spinal degeneration in asymptomatic populations. Am J Neuroradiol 2015;36(4):811-6. doi: 10.3174/ajnr.A4173.

44. Brinjikji W, Diehn FE, Jarvik JG, et al. MRI findings of disc degeneration are more prevalent in adults with low back pain than in asymptomatic controls: a systematic review and meta-analysis. Am J Neuroradiol 2015;36(12):2394-9. doi: 10.3174/ajnr.A4498.

45. Schistad EI, Espeland A, Rygh LJ, et al. The association between Modic changes and pain during 1-year follow-up in patients with lumbar radicular pain. Skeletal Radiol 2014;43(9):1271-9. doi: 10.1007/s00256-014-1928-0. 
46. Hellum C, Johnsen LG, Gjertsen $\varnothing$, et al. Predictors of outcome after surgery with disc prosthesis and rehabilitation in patients with chronic low back pain and degenerative disc: 2-year follow-up. Eur Spine J 2012;21(4):681-90. doi: 10.1007/s00586-011-2145-3.

47. Jensen RK, Leboeuf-Yde C, Wedderkopp $\mathrm{N}$, et al. Is the development of Modic changes associated with clinical symptoms? A 14-month cohort study with MRI. Eur Spine J 2012;21(11):2271-9. doi: 10.1007/s00586-012-2309-9.

48. Hancock MJ, Kjaer P, Kent P, et al. Is the number of different MRI findings more strongly associated with low back pain than single MRI findings?. Spine 2017;42(17):1283-8. doi: 10.1097/BRS.0000000000002102.

49. Steffens D, Hancock MJ, Maher CG, et al. Does magnetic resonance imaging predict future low back pain? A systematic review. Eur J Pain 2014;18(6):755-65. doi: 10.1002/j.1532-2149.2013.00427.x.

50. Teraguchi M, Yoshimura N, Hashizume H, et al. The association of combination of disc degeneration, end plate signal change, and Schmorl node with low back pain in a large population study: the Wakayama Spine Study. Spine J 2015;15(4):622-8. doi: 10.1016/j.spinee.2014.11.012.

51. Katulanda P, Jayawardena MA, Sheriff $\mathrm{MH}$, et al. Prevalence of overweight and obesity in Sri Lankan adults. Obes Rev 2010;11(11):751-6. doi: 10.1111/j.1467-789X.2010.00746.x.

52. Taylor JB, Goode AP, George SZ, et al. Incidence and risk factors for first-time incident low back pain: a systematic review and meta-analysis. Spine $J$

2014;14(10):2299-319.

doi: 10.1016/j.spinee.2014.01.026.

53. Currie SR, Wang J. More data on major depression as an antecedent risk factor for first onset of chronic back pain.

Psychol Med 2005;35(9):1275-82.

54. Patnala R, Clements J, Batra J. Candidate gene association studies: a comprehensive guide to useful in silico tools. BMC Genet 2013;14(1):39.

doi: 10.1186/1471-2156-14-39.

55. Battié MC, Videman T, Levälahti E, et al. Genetic and environmental effects on disc degeneration by phenotype and spinal level: a multivariate twin study. Spine 2008;33(25):2801-8.
56. Kalichman L, Hunter DJ. The genetics of intervertebral disc degeneration. Familial predisposition and heritability estimation. Joint Bone Spine 2008;75(4):383-7. doi: 10.1016/j.jbspin.2007.11.003.

57. Chan D, Song Y, Sham P, et al. Genetics of disc degeneration.

Eur Spine J 2006;15(3):317-25.

58. Videman T, Saarela J, Kaprio J, et al. Associations of 25 structural, degradative, and inflammatory candidate genes with lumbar disc desiccation, bulging, and height narrowing. Arthritis Rheum 2009;60(2):470-81. doi: 10.1002/art.24268.

59. Solovieva S, Lohiniva J, Leino-Arjas P, et al. Intervertebral disc degeneration in relation to the COL9A3 and the $I L-1 s s$ gene polymorphisms.

Eur Spine J 2006;15(5):613-9.

60. Perera RS, Dissanayake PH, Senarath U, et al. Variants of $A C A N$ are associated with severity of lumbar disc herniation in patients with chronic low back pain. PLoS One 2017;12(7): $\mathrm{e} 0181580$.

doi: 10.1371/journal.pone.0181580

61. Karppinen J, Daavittila I, Solovieva S, et al. Genetic factors are associated with Modic changes in endplates of lumbar vertebral bodies Spine 2008;33(11):1236-41.

62. Solovieva S, Kouhia S, Leino-Arjas P, et al. Interleukin 1 polymorphisms and intervertebral disc degeneration. Epidemiology 2004;15(5):626-33.

63. Kelempisioti A, Eskola PJ, Okuloff A, et al. Genetic susceptibility of intervertebral disc degeneration among young Finnish adults. BMC Med Genet 2011;12(1):153. doi: 10.1186/1471-2350-12-153.

64. Wu N, Chen J, Liu H, et al. The involvement of ADAMTS5 genetic polymorphisms in predisposition and diffusion tensor imaging alterations of lumbar disc degeneration. J Orthop Res 2014;32(5):686-94. doi: $10.1002 /$ jor.22582.

65. Yuan HY, Tang Y, Liang YX, et al. Matrix metalloproteinase-3 and vitamin $\mathrm{D}$ receptor genetic polymorphisms, and their interactions with occupational exposure in lumbar disc degeneration.

J Occup Health 2010;52(1):23-30.

66. Perera RS, Dissanayake PH, Senarath U, et al. Single nucleotide variants of candidate genes in aggrecan metabolic pathway are associated with lumbar disc degeneration and modic changes.

PLoS One 2017;12(1):e0169835. doi: 10.1371/journal.pone.0169835. 
67. Zhao J, Yang M, Shao J, et al. Association between VDR FokI polymorphism and intervertebral disk degeneration. Genomics Proteomics Bioinformatics 2015;13(6):3716. doi: 10.1016/j.gpb.2015.11.003.

68. Omair A, Holden M, Lie BA, et al. Treatment outcome of chronic low back pain and radiographic lumbar disc degeneration are associated with inflammatory and matrix degrading gene variants: a prospective genetic association study. BMC Musculoskelet Disord 2013;14(1):105.

doi: 10.1186/1471-2474-14-105.

69. Foulkes T, Wood JN. Pain genes. PLoS Genet 2008; 4(7).

doi: 10.1371/journal.pgen.1000086.

70. Samarakoon PS, Jayasekara RW, Dissanayake VH. The Sri Lankan genome variation database. Sri Lanka Journal of Bio-Medical Informatics 2011;2(1).

71. Kalichman L, Hunter DJ. The genetics of intervertebral disc degeneration. Associated genes. Joint Bone Spine 2008;75(4):38896. doi: 10.1016/j.jbspin.2007.11.002.

72. Mayer JE, Iatridis JC, Chan D, et al. Genetic polymorphisms associated with intervertebral disc degeneration. Spine J 2013;13(3):299-317. doi: 10.1016/j.spinee.2013.01.041.

73. Jarvik JG, Deyo RA. Diagnostic evaluation of low back pain with emphasis on imaging. Ann Intern Med 2002;137(7):586-97.

74. Chou R, Qaseem A, Owens DK, et al. Diagnostic imaging for low back pain: advice for high-value health care from the American College of Physicians. Ann Intern Med 2011;154(3):181-9. doi: 10.7326/0003-4819-154-3-20110201000008 . 